Int. J. Electrochem. Sci., 15 (2020) $16-25$

\title{
One-step synthesis of nitrogen, sulphur-codoped graphene as electrode material for supercapacitor with excellent cycling stability
}

\author{
Hangchun Deng, Meiwu Zhu, Tianxiang Jin, Chuanhong Cheng, Jugong Zheng*, Yong Qian* \\ Jiangxi Province Key Laboratory of Polymer Micro/Nano Manufacturing and Devices, East \\ China University of Technology, Nanchang, Jiangxi, 330013, China. \\ *E-mail: yqianecit@163.com (Y. Qian), jgzheng@ecit.cn (J. Zheng)
}

doi: $10.20964 / 2020.01 .13$

Received: 5 August 2019 / Accepted: 11 October 2019 / Published: 30 November 2019

Doping of carbon-based materials with heteroatoms is an efficient method to increase their electrocatalytic activities. In the present study, a one-step solvothermal method to prepare nitrogen and sulfur co-doped graphene (NSG) using thiourea and graphene oxide (GO) as raw materials, has been reported. For supercapacitor applications, NSG exhibited higher capacitive properties compared to undoped graphene (UG). The as-fabricated material displayed superior gravimetric specific capacitance of $176.5 \mathrm{~F} / \mathrm{g}$ at $1.0 \mathrm{~A} / \mathrm{g}$ and also showed outstanding long-term cyclic stability $(95.0 \%$ capacitive retention after 10000 cycles).

Keywords: nitrogen and sulfur co-doped graphene (NSG), supercapacitor, electrode material

\section{$\underline{\text { FULL TEXT }}$}

(C) 2020 The Authors. Published by ESG (www.electrochemsci.org). This article is an open access article distributed under the terms and conditions of the Creative Commons Attribution license (http://creativecommons.org/licenses/by/4.0/). 